\title{
GUY DE MAUPASSANT ANTE LA MASCARADA DE LA VIDA
}

\begin{abstract}
BRIGITTE LEgUeN
UNED. Madrid

bleguen@flog.uned.es

La soledad de la vida me da más frío que la soledad que habita la casa. Siento esta inmensa desorientación de los seres, el peso del vacío y en medio de esa desbandada del Todo, mi cerebro funciona con lucidez, con exactitud, deslumbrándome con la nada externa.
\end{abstract}

(Carta a su madre, Laure de Maupassant, enero de 1881)

\section{RESUMEN}

La obra de Guy de Maupassant abarea temas muy diversos según las épocas: él mismo se define como «un industrial de las letras» y resulta difícil elegir entre tantos posibles mundos de ficción. Este artículo se detiene principalmente en los fenómenos inconscientes y en la figura obsesiva del hombre alienado que de forma recurrente aparecen en sus cuentos.

PALABRAS CLAVE: Maupassant; siglo XIX: relato corto; literatura francesa.

\section{RÉsumé}

Loeuvre de Guy de Maupassant embrasse les thèmes les plus divers selon les périodes de sa vie: lui-même se définit comme "un industriel des Lettres» et il est difficile de faire un choix parmi tant de mondes possibles. Cet article s'intéresse principalement aux phénomènes inconscients et à figure obsessive de l'homme aliéné qui apparaît constamment dans ses contes.

MOTS CLEF: Maupassant, XIX siècle; textes courts; littérature française. 
Cuando Maupassant escribe esta carta tiene solamente treinta y un años y acaba de publicar, un año antes, en 1880, el relato que le lanza a la fama Bola de sebo. A pesar del éxito, de su aspecto jovial y robusto, este hombre joven aficionado a los deportes al aire libre y a las mujeres no consigue alcanzar la felicidad y considera el mundo con una mirada cargada de pesimismo y de melancolía. Encuentra en la lectura de las obras de Schopenhauer' ${ }^{1}$, recién traducido al francés, una comunidad de ideas que luego trasladará a sus cuentos y a la totalidad de su obra: se identifica con el nihilismo, la negación de todos los afectos, la visión de un mundo sin dioses, vacío y desolador. El rechazo de los valores establecidos y el ateísmo se extienden mientras tanto en la sociedad de la época y se intentan sustituir las antiguas costumbres por la fe en el progreso y en las ciencias, por el culto a la historia y, en el caso de la burguesía recién estrenada, por un nuevo concepto de confort moral y material. Guy de Maupassant rechaza la banalidad y el nuevo conformismo burgués y se adentra en un mundo mucho más atormentado, absurdo, trágico y doloroso. Confía en el conocimiento intuitivo que sólo se puede percibir en su totalidad a través de la experiencia erótica. Su aproximación existencial rompe decididamente con el intelectualismo y sale en busca del redescubrimiento del hombre como sujeto aislado e individualizado.

Maupassant es también un ávido lector de Sade el gran contramoralista que pone en evidencia la malignidad del ser humano y de la naturaleza que le rodea. A lo largo de todos sus escritos, tanto crónicas como artículos, cuentos o novelas, el escritor no se cansa de expresar su malestar en un mundo en el que no se siente en adecuación y que, según él, un dios monstruoso ha creado.

Junto a esta actitud cargada de desesperación, el escritor novel encuentra en Gustave Flaubert, el hombre de la famosa novela de la nada, un guía y un maestro que le inicia en el difícil oficio de escritor. Maupassant seguirá siempre a su mentor y como él buscará la perfección formal «un libro sin ataduras exteriores, que se sostendría por sí solo, apoyado en la fuerza interna de su estilo, tal y como lo hace la Tierra, que se mantiene en el aire sin que nada la sostenga, un libro que casi no tendría tema o al menos cuyo tema resultaría casi invisible en la medida de lo posible. Las obras más bellas son las que tienen la menor cantidad posible de materia: cuanto más cerca queda la expresión del pensamiento, cuanto más se adecue a la palabra dicho pensamiento, sin que se note, más bello resultará. Creo que el porvenir va en esta dirección» (carta de Flaubert a su amiga Louise Collet, 16 de enero 1852). Esta reflexión constituye una breve definición de lo que es para el maestro Flaubert la literatura. Su joven discípulo Maupassant compartirá esta visión que se aparta en muchos puntos de las consignas naturalistas difundidas por parte de los miembros del llamado Grupo de Médan.

También influye en los primeros años de formación la presencia de la madre, Laure de Maupassant, quien se encarga de supervisar los primeros pasos de su hijo en el difícil mundo de las letras. En cuanto al padre, Gustave de Maupassant, su papel queda en segundo plano ya que el matrimonio se separa en 1860 , dejando a los dos hijos al cuidado

Arthur Schopenhauer (1788-1860) fue traducido al francés a partir de 1877. Un amigo cercano a Maupassant, Jean Bourdean tradujo en 1880 pensées, maximes et fragments. La filosofía de Schopenhauer influenció a Guy de Maupassant desde muy joven y existen numerosas alusiones al pensamiento del filósofo alemán en su obra. 
de la madre, en Normandía. Entre los dos «Gustave», el joven Guy elige a Gustave Flaubert aunque siga manteniendo buenas relaciones con su padre biológico. Hereda la fragilidad nerviosa del lado materno y sigue los pasos del padre en su incesante persecución del placer. A Hervé de Maupassant, su único hermano, le une una estrecha relación que permanecerá hasta la muerte de éste en 1889.

A pesar de la sífilis que consume su vida y de una sensibilidad a flor de piel o precisamente gracias a ello, el escritor encuentra en el arte su salvación. No forma parte de los que en Francia se denominan con cierta delectación «los intelectuales». Se deja guiar por las sensaciones, en busca de la emoción que encuentra en la belleza, en el arte, en las mujeres, en los paisajes. Desea, dice, «breves y raras y violentas revelaciones de la belleza» (Carta a su amigo J.Bordeau, 1889). Emprende una busca dionisíaca que le lleva a las Playas de Etretat, en el seno de su Normandía natal. Le gusta el mar, el barco, las armas. Navega también por el Sena con sus amigos los «canotiers». Es misógino, solitario y sensual, independiente en sus juicios y en sus relaciones. Los vínculos que le unen a la Escuela Naturalista y al grupo de Médan se rompen en cuanto muere su padre adoptivo Gustave Flaubert en 1880.

A partir de entonces sigue su trayectoria en solitario y se aleja de las escuelas. Dice a Paul Alexis, en una carta de 1877 «no creo más en el Naturalismo y en el realismo que en el Romanticismo»y añade que los realistas deberían denominarse «ilusionistas»².

Es significativo el poco interés que pone en teorizar o simplemente en exponer sus opiniones literarias. Su Estudio sobre la novela que precede a la novela Pierre et Jean (1887) constituye su única aportación importante en esta materia junto con algunos artículos de prensa. Estamos muy lejos del dogmatismo zoliano, lo que no impide que el joven escritor se impregne de todas las influencias que le rodean: la huella aún fresca del Romanticismo, la influencia de Baudelaire al que cita repetidas veces. De los románticos hereda los nuevos criterios estéticos que recuperará toda su generación: no hay temas tabúes, lo feo puede ser bello, todo es relativo y depende del prisma desde donde se mire. A continuación el realismo propone una renovada descripción de la realidad; la de la Historia y de la sociedad contemporánea. La Prensa recién democratizada introduce en los periódicos las novelas por entregas. Junto a los folletines, los relatos cortos conocen un renovado éxito.

El género corto de moda responde también a la evolución del gusto artístico en general, orientado hacia la anécdota sacada de los sucesos recientes, hacia la pequeña crónica de sociedad, el fragmento de vida (la famosa «tranche de vie»), los tópicos heredados de las «fisiologías» realistas, lo instantáneo ${ }^{3}$.

Maupassant, como muchos de sus atormentados contemporáneos, busca remedios a su angustia y se siente preso del enorme desencanto que embarga a la sociedad francesa en el período de la post-Revolución de 1848. Busca en la dirección de las ciencias o de las seudo-ciencias, en el magnetismo avalado por Messmer, en el ocultismo que atrae a

\footnotetext{
${ }^{2}$ Esta reflexión procede de su único texto tébrico titulado Etude sur le roman, prólogo a la novela Pierre et Jean, septiembre de 1887 .

3 Jules Lemaitre escribe en les contemporains, «tenemos cada vez más prisas; nuestra mente anhela placeres rápidos o emociones súbitas; queremos novelas lo más condensadas a ser posible e incluso, en el peor de los casos, se reduce en lugar de condensar».
} 
Hugo, Villiers de L'Isle-Adam y a continuación Huysmans. Maupassant además acude a los seminarios organizados por Charcot como también lo hizo Sigmund Freud con algunos años de diferencia.

El Naturalismo refuerza e intensifica ciertos procedimientos realistas ya instaurados y aspira a inspirarse en las ciencias naturales para copiar su método de análisis. La conocida Novela experimental de Zola pretende precisamente calcar la medicina experimental de Claude Bernard y llevar la literatura al mismo plano que la ciencia ${ }^{4}$.

Obviamente existen también diferencias capitales con la etapa anterior - la del Realismo- que coinciden con importantes variaciones en las condiciones históricas y socio-culturales. Se adhieren nuevos territorios a explorar, en particular todos los espacios referentes a los márgenes de la sociedad, y a la conciencia individual y colectiva. Pero allí valen más los matices y las diferencias individuales que son las que determinan el carácter único y original de cualquier obra de arte en el seno de la modernidad. Flaubert, Vallès o Maupassant abarcan el espacio literio de un modo personal e intransferible. La época se caracteriza precisamente por su diversidad creativa y por la libertad con que se expresa su imaginario. Existen sin embargo aspectos dominantes que convienen al conjunto de los artistas: una cierta conciencia del desorden social e individual, una renovada voluntad de experimentar los límites, los márgenes de la realidad y su relación con el imaginario, tanto en el plano de la conciencia como en el territorio aún poco explorado del inconsciente. El movimiento, no nos quepa duda, traspasa obviamente el espacio estrictamente nacional. Este periodo coincide también con los progresos de la psiquiatría, con nuevas nociones y definiciones de la salud mental y de la higiene ${ }^{5}$. La presencia del cuerpo durante el siglo XIX cobra nuevos significados. El de la mujer, en particular, evoluciona sorprendentemente hasta llegar a las primeras «garçonnes» que tanto escandalizarán a ciertos sectores de la sociedad. Se estudian desde otros enfoques las correspondencias entre la fisionomía y la personalidad, entre lo visible y lo invisible, y nos dirigimos hacia una nueva cultura de lo somático. Las investigaciones acerca de la psique y el novísimo campo del psicoanálisis (los primeros estudios de Freud son de 1895) se propagan. No es entonces puro azar si Maupassant crea lo que Louis Vax denomina «un fantástico interior» que se nutre de las pulsiones más profundas que desarrollará apoyándose en las nuevas ciencias o seudo-ciencias ${ }^{6}$. Maupassant sigue la evolución del pensamiento europeo que se orienta de modo convergente a lo largo de la década de los 80 hacia la elaboración desde un enfoque racionalista de los fenómenos inconscientes ya percibidos de modo más intuitivo tiempo atrás. ¿Cómo no vislumbrar en la obra de Maupassant la presencia especular del inconsciente al recorrer estos relatos poblados de personajes empujados por fuerzas que no controlan? Las apariencias de la realidad objetiva - situaciones concretas, paisajes y ciudades, personajes pintorescos o singulares, etc...-, están rápidamente trascendidas y reconducidas hacia otra realidad de la

\footnotetext{
${ }^{4}$ la novela le roman expérimental de Emile Zola se publicó por primera vez en 1878 en Le Voltaire.

${ }_{5}$ Véanse sobre este tema tan revelador el libro de Philippe Perrot, le travail des apparences. Le corps féminin, $X V I I I^{\circ}$ y XIX ${ }^{\circ}$, col., Points «histoire», ed. Seuil, París, 1984

${ }^{6}$ El término de psiquiatra como médico que trata diversos típos de alineación mental, se emplea a partir de 1802 en Francia.
} 
conciencia que filtra, de las sucesivas pantallas que las modifican, de la sensibilidad y habilidad del lector?.

El novelista asume el carácter ilusorio de la realidad y dice en su Etude sur le roman lo siguiente:

«Cada uno de nosotros mira simplemente al mundo como una ilusión y el escritor tiene como única misión la de reproducir fielmente dicha ilusión con todos los procedimientos artísticos que ha adquirido y que están a su alcance» ${ }^{8}$.

El terreno neurótico sobre el que se edifica la obra y la ciclotimia del creador de la misma explican ampliamente el lugar que ocupa lo fantástico desde los principios de la obra así como la innegable intuición del autor ante los fenómenos inconscientes que Freud atribuye a ciertas personas, en particular a los artistas y a los paranoicos. Conviene sin embargo recordar que la crítica, confundiendo más de lo debido al hombre con su obra, tiende con cierta unanimidad a presentar la escritura como exutorio de la enfermedad o incluso como premonición de la misma.

La época cultiva todos los «ailleurs», otros lugares, otras dimensiones, y no cabe duda que aquella búsqueda coincide con la crisis que castiga a la sociedad francesa vencida en 1870; se trata de buscar fuera lo que ya no puede ofrecer el estrecho marco nacional. Todas las negaciones se acumulan: negación de los valores religiosos y morales, fin del antropomorfismo, de las agotadas convicciones patrióticas. Todo ello engendra un «mal de vivir", un aburrimiento mustio muy fin de siglo que lleva a un sentimiento reafirmado de la nada, más cercano del absurdo sartriano que del mal du siècle romántico. Acontece en un período muy cercano al actual en el que una sociedad desorientada y desencantada busca refugio en los paraísos artificiales (éter, opio, absenta) y en el erotismo. Una cierta cultura del malestar y de la neurosis, el espíritu de aventura aplicado a la experiencia de los límites, engendran el gusto por lo fantástico y lo raro como objeto estético ${ }^{10}$.

Maupassant es un hombre de su época en todo. Busca y cultiva lo fantástico sin erradicar la verosimilitud que le sirve de contrapunto y de elemento subversivo; juega con la indecisión y la duda. En el seno de la normalidad, incluso en medio de la mayor banalidad, el azar (siempre maligno en los cuentos) le brinda la ocasión de un encuentro con la pavorosa verdad. Lo imprevisible surge por sí mismo o por la mediación de los objetos más cotidianos. El miedo e incluso la angustia se manifiestan en los recovecos de lo insípido. Cuánto más pobre en detalles resulta el espectáculo más espectacular resultará el desenlace. La cotidianeidad anodina sobrecoge a la víctima desarmada. Allí está precisamente la modernidad del procedimiento que se basa en la incierta identidad del personaje y en su precario equilibrio.

7 Véase sobre este tema en particular los trabajos de André Vial en particular su Tesis sobre Maupassant y el libro de louis Vax titulado la séduction de l'étrange. Etude sur la littérature fantastique. PUF, 1965.

Sobre la relación de Maupassant con las manifestaciones del inconsciente ver el estudio de Pierre Bayard, Maupassant juste avant Freud, éd. Minuit, col. Paradoxe, 1994.

"Se trata de lo que Freud denomina «saber endopsíquico". Se trata de una intuición particular hacia ciertos fenomenos inconscientes, por parte de individuos determinados, como artistas y paranoicos.

${ }^{10}$ Escritores como Jean Lorrain, Rémy de Gourmont, Catulle Mendés ilustran a través de sus obras la atracción por las situaciones extremas con motivos como el sexo, la droga, y la muerte. 
Maupassant introduce la confusión con una llamada al otro que llevamos dentro; la locura de los personajes cuestiona la unicidad, la estabilidad de la personalidad y nos hace dudar'".

Mientras que en el psicoanálisis freudiano el inconsciente está ligado a lo no visible, a lo que se oculta detrás de lo visible y que habrá que desvelar para luego interpretarlo, en Maupassant la presencia del inconsciente, el otro, el doble que pone en acción lo no visible, se manifiesta sin cesar en un exceso de visibilidad y de legibilidad. Está estrechamente vinculado al tema del encuentro y del descubrimiento de la identidad oculta o de la identidad dudosa. El novelista insiste en mostrar que no existen encuentros anodinos ya que no existe el otro anodino. Todo produce sentido, en particular en la encrucijada de dos ejes obsesivos: el deseo y la locura.

La cuestión tan a menudo aludida a lo largo de toda la obra, el tema de la identidad dudosa, nos remite, en el nivel del enfoque psicoanalítico, a la obra de Otto Rank quien descartó la sexualidad como elemento más determinante y crucial del funcionamiento psíquico. Para Maupassant lo sexual no resulta tabú aunque sí recoge sin cesar el poco control que el hombre tiene sobre su propia conducta y la vertiginosa versatilidad de sus comportamientos.

Los personajes son los actores de un desenlace cargado de fatalidad cuyo movimiento apenas controlan y que no pueden explicar. Esta voluntad por parte del autor de mantener la máxima ambigüedad queda reflejada en la segunda versión de su famoso cuento El Horla en la que el autor renuncia a la explicación científico-médica que permitía autentificar el discurso del narrador.

La risa ocupa poco lugar en esta obra en la que el hombre que describe aparece siempre como alienado, perseguido, ensombrecido. Sólo queda lugar para una cierta risa ácida y cruel. A lo largo del siglo xix asistimos a la vuelta a la tradición de la novela cómica, recogida por diversos autores como Théophile Gautier con su Romans gauguenards, o Alphonse Daudet con sus Contes $d u$ Lundi y este intertexto humorístico impregna también la obra de Maupassant sobre todo en su primera época.

La pasión misógina de Maupassant hacia el género femenino es de todos conocida. Aquella atracción queda muy bien reflejada en su obra y se centra en un personaje femenino cuyo atractivo sexual ocupa un lugar privilegiado y obsesivo. La prostituta, la esclava mora, la mujer fatal abundan en sus cuentos; es por regla general una amenaza para el hombre: es una mujer vampiro que llega a poner en peligro el sexo mismo del varón. Todo aquello responde una vez más a la estética de la época que encontramos también en autores como Goethe (la novia de Corinteo), en Mérimée (la Guzla) o en Théophile Gautier (La muerta enamorada)..., pintores como Gustave Moreau o Knopp siguen las mismas tendencias.

La figura femenina está a menudo asociada al fetichismo, pero a un fetichismo idealizado al que repugna lo grotesco, lo irrisorio o lo vulgar. Estamos a años luz del sórdido personaje de Gustave Mirbeau, el señor Rabour, en la novela Diario de una criada fascinado por las botas de las mujeres. Maupassant no busca al fetichista tipo tal y como lo describen Charcot y Magnan, obsesionado por las nalgas, los gorros de noche,

"Marie-Claire Ropars-Wuillenmier en su prólogo a la edición de la novela Pierre et jean, Livre de poche, éd. Albin Michel, parís, 1984, alude al tema del doble. 
los delantales blancos o los clavos en las suelas de los zapatos. Quiere poetizar el acto fetichista y liberarlo de la monótona repetición aplicada a objetos feos o carentes de belleza artística.

Sin embargo y a pesar de su extrema misoginia, Maupassant sale en defensa de ciertos derechos que todavía no se reconocían: el derecho al divorcio, el derecho a la igualdad entre hombres y mujeres, e incluso el derecho al aborto; defiende a las prostitutas y denuncia la miseria social que les rodea aunque nunca sitúa sus relatos en el seno de la clase obrera. Le atraen más los personajes víctimas de la crueldad sádica de sus opresores: animales maltratados, marginales perseguidos, pobres de espíritu,...

La angustia y la soledad del ser humano constituyen el telón de fondo del conjunto de la obra. Maupassant insiste en la incomunicación que rodea la vida humana, en la alienación y en el aislamiento en el que quedan atrapados sus protagonistas. Es plenamente consciente de la ambigüedad de lo que llamamos «realidad» y procura elegir espacios propicios a la ensoñación: el paisaje acuático, París «l'immonde cité» como la llama Baudelaire y su Normandía natal.

Dado el tipo de género, su brevedad, el tiempo se reduce casi siempre a un momento fugaz y huidizo, incluso cuando abarca una época más larga de la vida humana.

¿Cuentos o novelas cortas? Resulta difícil delimitar y definir los relatos cortos de Maupassant. El término anglosajón «short story» sigue siendo la mejor manera de acabar con una polémica que los mismos escritores de la generación de Maupassant no solucionaron, ya que emplearon indistintamente las dos palabras para sus obras breves. Maupassant insiste en el carácter oral del cuento como tal y en el tipo de escritura más «literaria» de la novela corta. Existen también una serie de elementos propios a este tipo de relatos: brevedad, condensación, unidad en torno a una única acción, número limitado de personajes y de espacios. Ciertos relatos como El cordelillo engendran a su vez otro cuento o relato. Este tipo de historia implica la presencia de un narrador y de un público cuya participación ostensible adopta el tono del relato oral (como por ejemplo el cuento titulado La Felicidad). El narrador en casos semejantes ha podido ser testigo de excepción o protagonista de la historia. La aventura siempre pertenece a un tiempo acabado y la labor de quien lo cuenta es precisamente la de devolver su presencia a los acontecimientos, su «aquí y ahora», para revivirlos desde una nueva perspectiva. En tal caso, la imprevisibilidad, el efecto de sorpresa, dependen por completo del discurso, de la elocuencia de quien narra y de la finalidad moral o filosófica del cuento.

Muchos consideran el relato corto como una infra-novela, como el campo de experimentación previo a la novela. Ocurre frecuentemente que ciertos capítulos de novelas procedan de relatos cortos adaptados. Kafka lo hizo en su novela América, Chandler igualmente incorporó a sus novelas policíacas relatos cortos ya publicados anteriormente. Maupassant reconvierte una misma historia con formas diferentes y con procedimientos oblicuos y mixtos (lo vemos concretamente en Una vida y en Bel Ami).

En medio de la enorme producción de un autor como Maupassant algunos textos siguen respondiendo a las inquietudes del lector contemporáneo inmerso en la post-modernidad, consciente de la ambigua relación que establece el individuo con la sociedad que le rodea. Textos en los que el autor describe a un individuo alienado, preso de sus deseos y pasiones, un hombre de poca fe, atento a la realidad que le rodea: amor, muerte, locura, suicidio, soledad, crueldad, guerra... 
La escritura maupassiana resulta extremadamente moderna en su forma de enfocar todo aquel mundo oscuro y desgarrador con una peculiar y sutil intuición de los fenómenos inconscientes, unos cuantos años antes de que el psicoanálisis los formule teóricamente. Se trata para el novelista de percibir «uno de esos misteriosos e inconscientes recuerdos de la memoria que nos representan a menudo cosas desatendidas por nuestra conciencia, y que nuestra inteligencia pasó por alto» (Magnetismo).

El autor nos ofrece una concepción original de la psique junto a una fiel representación de la ferocidad humana, siguiendo los pasos de su maestro Flaubert. Es como él, según otro importante escritor de la época, Paul Bourget, « un nihilista hambriento de lo absoluto». Su profético encuentro en Etretat, tierra de la infancia, con Swinburne y Powel, su fascinación temprana ante la estética prerrafaelista de Rosetti, Burne-Jones o Gustave Moreau $^{12}$; sus lecturas de Nerval, Poe y Hoffmann que guían sus primeros pasos, pesan más sin duda en su recorrido literario que las famosas veladas de Médan.

Maupassant sigue siendo nuestro contemporáneo. Con él todavía nos podemos identificar y encontramos en sus historias parte de la nuestra. Nos ofrece la libertad de imaginar y nos devuelve a todas las pasiones que agitan la humanidad desde siempre. Asume la polisemia de esta realidad y la ambivalencia de las emociones a las que reserva un lugar privilegiado en el marco de una cultura dividida entre la pulsión y la razón.

\section{REFERENCIAS BIBLIOGRÁFICAS}

\section{Obras $^{13}$}

Choses et autres. Choix de chroniques littéraires et mondaines, París, Le Livre de Poche Classique, 1993.

Chroniques et récits de voyage, Bruselas, Complexe, 5 vols., 1993.

Correspondance Flaubert-Maupassant, París, Flammarion, 1993.

Cuvres, París, Club de l'Honnête Homme, 4 vols., 1988.

Euvres Complètes, éd. L. Forestier, París, Gallimard, La Pléiade, 3 vols., 1974-1987.

\section{Estudios críticos}

BAYARD, P., Maupassant juste avant Freud, París, Minuit, 1994.

BESNARD-COURSODON, M., Etude thématique et structurale de l' ceuvre de Maupassant: le piège, París, Nizet, 1973.

12 Ernst. H. Gombrich en su Historia del Arte, Alianza Editorial, Madrid, 1990, explica cómo se constituye la hermandad prerrafaelista (p. 404) «creyendo que el arte se había vuelto insincero por influjo de Rafael, y que su misión era volver a la edad de la fe, este grupo de amigos se dio a si mismo el nombre de «Hermandad prerrafaelista». Uno de sus miembros mejor dotado fue el hijo de un refugiado italiano, Dante Gabriele Rossetti $(1828-1882)$

${ }^{13}$ Existen numerosas colecciones francesas de bolsillo como las editadas por Livre de Poche, Folio o GFFlammarion; entre los estudiosos encargados de las ediciones más recientes se debe tener en cuenta los nombres de Louis Forestier, Marie-Claire Blancquart, Pierre Coigny, Mariane Bury y Wald Lasowski.En lengua castellana existen numerosas antologías temáticas de gran interés, en particular las traducciones de Esther Benitez en Alianza Editorial. 
Blanquart, M-C., Maupassant conteur fantastique, París, Lettres Modernes, Minard, 1976.

Bury, M., La poétique de Maupassant, París, SEDES, 1994.

CASTElla, Ch., Structures romanesques et vision sociale chez Maupassant, Lausana, L'âge d'homme, 1972.

Castex, P-G., Le conte fantastique en France de Nodier à Maupassant, París, José Corti, 1957.

Colgny, P., Maupassant, l' homme sans Dieu, Bruselas, Renaissance du livre, 1968.

Danger, P., Pulsion et désir dans les romans et nouvelles de Guy de Maupassant, París, Nizet, 1993

GAADAR, S., Figures et poétique de la folie dans les contes cruels et fantastiques de Maupassant, Villeneuve d'Ascq, Presses Universitaires du Septentrion, 1997.

Greimas, A. J., Maupassant, la sémiotique du texte. Exercices pratiques, París, Le Seuil, 1976.

POYET, T., L'héritage Flaubert-Maupassant, París, Kimé, 2000.

SAVINIO, A., Maupassant e "l'altro ", Milán, Adelphi Edizioni, 1975.

(Hay una edición española, Maupassant y «el otro», traducción de G.Sánchez Ferlosio, Barcelona, Bruguera, 1983). 